\title{
Myocardial remodeling after infarction: the role of myofibroblasts
}

Citation for published version (APA):

van den Borne, S. W. M., Diez, J., Blankesteijn, W. M., Verjans, J., Hofstra, L., \& Narula, J. (2010). Myocardial remodeling after infarction: the role of myofibroblasts. Nature Reviews Cardiology, 7(1), 30-37. https://doi.org/10.1038/nrcardio.2009.199

Document status and date:

Published: 01/01/2010

DOI:

10.1038/nrcardio.2009.199

Document Version:

Publisher's PDF, also known as Version of record

Document license:

Taverne

Please check the document version of this publication:

- A submitted manuscript is the version of the article upon submission and before peer-review. There can be important differences between the submitted version and the official published version of record.

People interested in the research are advised to contact the author for the final version of the publication, or visit the DOI to the publisher's website.

- The final author version and the galley proof are versions of the publication after peer review.

- The final published version features the final layout of the paper including the volume, issue and page numbers.

Link to publication

\footnotetext{
General rights rights.

- You may freely distribute the URL identifying the publication in the public portal. please follow below link for the End User Agreement:

www.umlib.nl/taverne-license

Take down policy

If you believe that this document breaches copyright please contact us at:

repository@maastrichtuniversity.nl

providing details and we will investigate your claim.
}

Copyright and moral rights for the publications made accessible in the public portal are retained by the authors and/or other copyright owners and it is a condition of accessing publications that users recognise and abide by the legal requirements associated with these

- Users may download and print one copy of any publication from the public portal for the purpose of private study or research.

- You may not further distribute the material or use it for any profit-making activity or commercial gain

If the publication is distributed under the terms of Article $25 \mathrm{fa}$ of the Dutch Copyright Act, indicated by the "Taverne" license above, 


\title{
Myocardial remodeling after infarction: the role of myofibroblasts
}

Susanne W. M. van den Borne, Javier Diez, W. Matthijs Blankesteijn, Johan Verjans, Leo Hofstra

and Jagat Narula

\begin{abstract}
Myofibroblasts have characteristics of fibroblasts and smooth muscle cells: they produce extracellular matrix and are able to contract. In so doing, they can contribute to tissue replacement and interstitial fibrosis following cardiac injury. The scar formed after myocardial injury is no longer considered to be passive tissue; it is an active playground where myofibroblasts play a role in collagen turnover and scar contraction. Maintaining the extracellular matrix in the scar is essential and can prevent dilatation of the infarct area leading to heart failure. On the other hand, extracellular matrix deposition at sites remote from the infarct area can lead to cardiac stiffness, an inevitable process of myocardial remodeling that occurs in the aftermath of myocardial infarction and constitutes the basis of the development of heart failure. Defining molecular targets on myofibroblasts in conjunction with establishing the feasibility of molecular imaging of these cells might facilitate the early detection and treatment of patients who are at risk of developing heart failure after myocardial infarction.
\end{abstract}

Van den Borne, S. W. M. et al. Nat. Rev. Cardiol. 7, 30-37 (2010); published online 1 December 2009; doi:10.1038/nrcardio.2009.199

\section{Introduction}

The myocardium is a highly organized structure that contains several cell types, such as cardiomyocytes, fibroblasts and endothelial cells, and vascular and neuronal networks. Interspersed between these elements, the interstitium comprises a complex extracellular matrix (ECM) of structural, adhesive and matricellular proteins and cell-surface receptors (integrins) within a hydrated proteoglycan and glycosaminoglycan-rich milieu. ${ }^{1}$ The collagen proteins found in the myocardium include types I, III, IV, $\mathrm{V}$ and VI, with structural type I collagen being the most predominant $(>70 \%)^{2}$

The balance between the synthesis and degradation of collagen during cardiac remodeling determines its turnover, and, in the post-injury state, this process is regulated predominantly by myofibroblasts. Mainly differentiated from fibroblasts, these cells express contractile proteins and exhibit migratory, proliferative and secretory properties. ${ }^{3,4}$ They respond to mechanical stretch, autocrine and paracrine factors generated within the myocardium (for example, vasoactive peptides, such as angiotensin II, and growth factors, such as transforming growth factor- $\beta$ [TGF- $\beta]$ ) and hormones derived from the circulation (for example, aldosterone). In addition, a number of studies showed that myofibroblasts are responsive to proinflammatory cytokines (for example, tumor necrosis factor [TNF], interleukin [IL]-1, IL- 6 and TGF- $\alpha$ ) secreted by inflammatory cells, such as macrophages, $\mathrm{T}$ cells and mast cells. ${ }^{4,5}$ The response of myofibroblasts to the aforementioned factors involves changes in their rates of proliferation and migration, and

Competing interests

The authors declare no competing interests. modifications in their capacity to synthesize and secrete collagen precursors, extracellular collagen-processing enzymes and matricellular proteins. ${ }^{4}$

Collagen is synthesized and secreted by myofibroblasts as procollagen precursor, and is converted to mature collagen by proteolytic reactions catalyzed by specific procollagen proteinases. ${ }^{6}$ Types I, III and V collagen molecules are rapidly assembled into collagen fibers through chemical reactions that occur spontaneously or are catalyzed by the copper-dependent amine oxidase lysyl oxidase. ${ }^{7}$ The degradation of collagen fibers takes place after a half-life of 80-120 days, and is mediated by the family of zincdependent matrix metalloproteinases, namely collagenases and gelatinases. ${ }^{8}$

Owing to its dynamic nature, the composition and morphology of the cardiac collagen network can be reversibly modified to adapt to cardiac injury. The replacement fibrosis initially supports ventricular morphology but, eventually, irreversible, maladaptive changes of the network occur, which affect the amount of collagen, the collagen phenotype, and the degree of collagen crosslinking. In particular, myocardial fibrosis is characterized by an increased deposition of type I collagen fibers, showing an increased degree of crosslinking, within the interstitial space in areas remote from initial insult. ${ }^{9}$

In this Review, we discuss the mechanisms of both beneficial and adverse myocardial remodeling after myocardial infarction (MI), processes in which myofibroblasts are integrally involved. Strategies for imaging myofibroblasts, which might be useful for the early detection of adverse remodeling events and for predicting the likelihood of the occurrence of heart failure, are also briefly discussed. 


\section{The wound healing process after MI}

Wound healing after MI entails a cascade of events that involves a complex interplay between several different cell types, including inflammatory cells, endothelial cells, fibroblasts and myofibroblasts. In acute injury, the death of cardiomyocytes invokes the recruitment at the infarct border of inflammatory cells, which remove the necrotic cell debris by phagocytosis. Granulation tissue begins to form around the fourth day after MI-depending on the species-and consists of inflammatory cells, newlyformed blood vessels (to restore the blood supply) and fibroblast-like cells that deposit collagen. Eventually, this granulation tissue matures into a scar that is devoid of inflammatory cells but rich in ECM and fibroblast-like cells (fibrotic tissue). ${ }^{9}$ Tacitly, the scar tissue in the infarct has been perceived as a passive replacement for the lost cardiomyocytes with little biological activity, but this tissue is being increasingly recognized as a site of activity wherein fibroblast-like cells continue to be involved in collagen turnover and scar-tissue contraction..$^{9,10}$ The persistence of fibroblast-like cells in the infarct area is a prerequisite to ensure maintenance of the ECM in the scar, which is subjected to mechanical stress as well as wear and tear in the beating heart.

\section{Myofibroblast activity after MI}

Myofibroblasts are found in the granulation tissue in the infarct region; there are no reports of myofibroblasts activity in the healthy, uninjured myocardium. ${ }^{4}$ These cells replace the damaged and lost cardiomyocytes that cannot be regenerated, and help to produce a strong scar tissue. They also possess contractile properties and are associated with a smaller and stronger scar area that helps to prevent infarct expansion and ventricular dilatation. However, the inevitable production of collagen by myofibroblasts in the remote area contributes to adverse ventricular remodeling and unfavorable outcomes. Unlike in skin and other organs, in which myofibroblasts are relatively shortlived, these cells persist for a long time in the heart at sites remote to the infarct, with the net balance in favor of ECM deposition. Might targeted pharmacological intervention be able to influence healing characteristics favorably?

\section{The origin of myofibroblasts}

In order to modulate the process of myofibroblast proliferation to reduce the drawbacks without compromising the benefits, we need to understand the process more comprehensively. Myofibroblasts are thought to be derived from multiple sources (Figure 1). ${ }^{11}$ In addition to pre-existing local fibroblasts that can differentiate into myofibroblasts, epithelial and endothelial cells can adopt a myofibroblast phenotype through the processes of epithelial-mesenchymal transition and endothelialmesenchymal transition, respectively. ${ }^{12,13}$ Furthermore, circulating fibroblast-like cells are thought to be derived from bone-marrow stem cells; these blood-borne mesenchymal stem-cell progenitors have a fibroblast-myofibroblast-like phenotype and are called fibrocytes. ${ }^{14}$ Myofibroblasts of different origins are thought to participate with resident mesenchymal cells in the repair process; ${ }^{15}$ however, the

\section{Key points}

- Myofibroblasts have characteristics of fibroblasts and smooth muscle cells and contribute to tissue replacement and interstitial fibrosis following cardiac injury

- Maintaining the extracellular matrix in the scar is essential and can prevent dilatation of the infarct area

- Extracellular matrix deposition at sites remote from the infarct area can contribute to the development of cardiac remodeling and heart failure

- Defining molecular targets on myofibroblasts in conjunction with establishing the feasibility of molecular imaging might facilitate early detection and treatment of patients at risk of developing heart failure after myocardial infarction

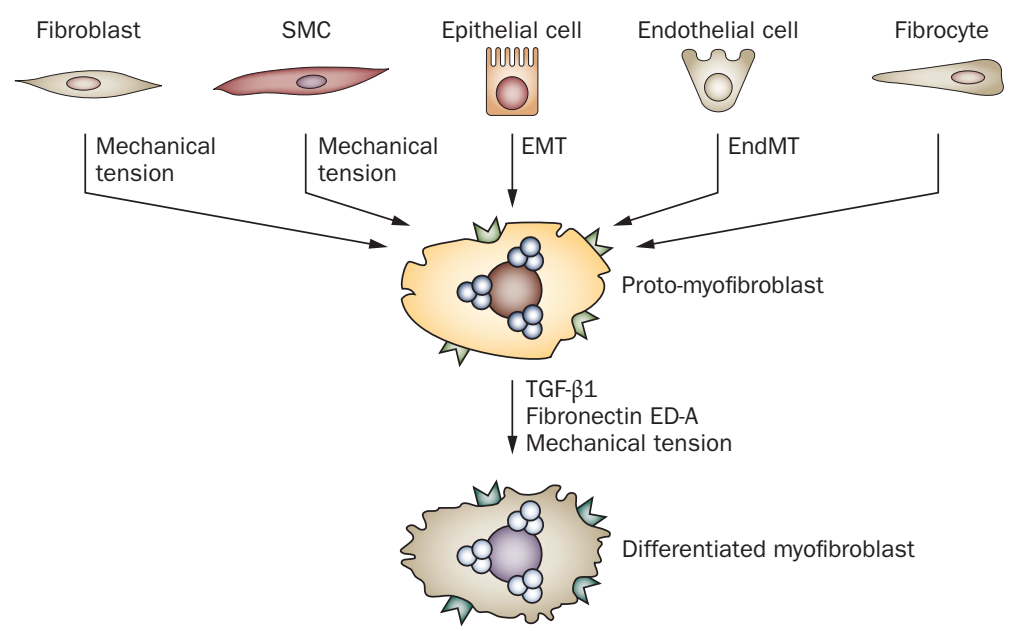

Figure 1 | Myofibroblast precursors and characteristics. Myofibroblasts can be derived from various cell types. In addition to resident fibroblasts, they can also be derived from SMCs, epithelial and endothelial cells, and blood-borne mesenchymal stem-cell progenitors (fibrocytes). In response to specific stimuli, these cells can transform into proto-myofibroblasts, which, in turn, can differentiate into myofibroblasts in response to TGF- $\beta 1$, fibronectin ED-A and mechanical stretch. Myofibroblasts are characterized by the presence of $\alpha$-smooth muscle actin, supermature focal adhesions (with integrins), angiotensin II type 1 receptor, and their ability to produce collagen. Abbreviations: EMT, epithelial-mesenchymal transition; EndMT, endothelial-mesenchymal transition; SMC, smooth muscle cell; TGF- $\beta 1$, transforming growth factor- $\beta 1$.

relative contribution of each of these populations remains to be established. As an example, the relative contribution of bone marrow-derived fibrocytes to the myofibroblast content of the infarct area has been estimated between 0 and 57\%. ${ }^{4}$ Primary fibroblasts isolated from a number of different organs comprise a vastly diverse group of cells and it is unlikely that fibroblasts from kidney behave in precisely the same way as do those from lung, heart or skin. ${ }^{16}$ As such, there is a growing interest in dissecting the role of the various myofibroblast subpopulations in tissue regeneration and fibroproliferative diseases. ${ }^{11}$

\section{Myofibroblast differentiation after MI}

Under normal circumstances, resident cardiac fibroblasts have no contractile microfilaments or stress fibers, exhibit few or no actin-associated cell-cell and cell-matrix contacts and produce minimal amounts of ECM. ${ }^{17}$ In the aftermath of MI, fibroblasts are activated to differentiate into myofibroblasts, which converge on the damaged region and accelerate the synthesis of various ECM proteins, such 

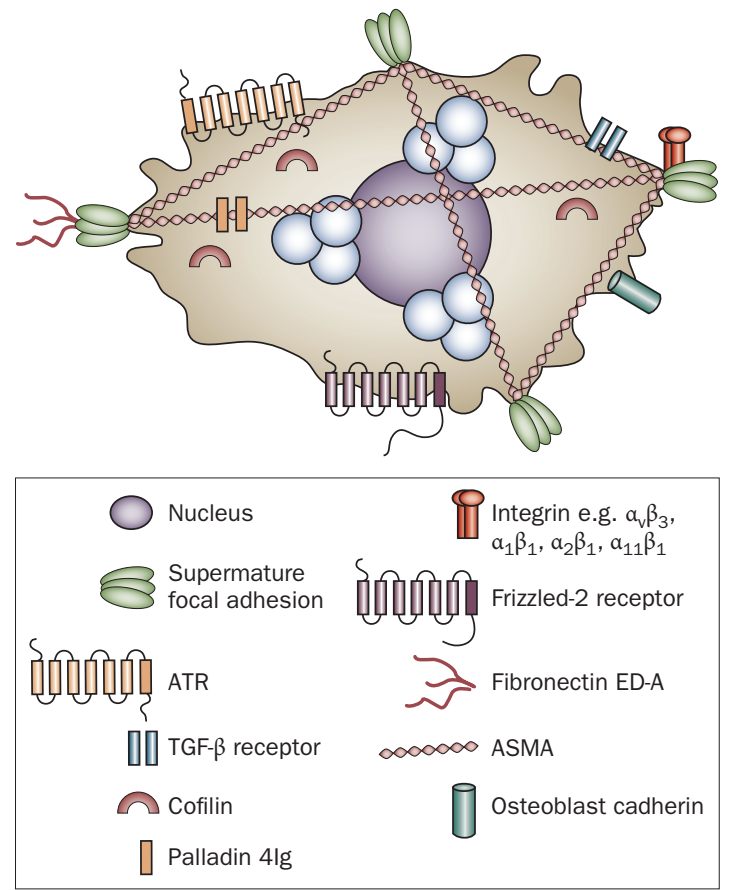

Figure 2 | Markers of myofibroblast differentiation. Differentiated myofibroblasts express several targets that might be of interest for molecular imaging. The ATR, Frizzled-2 receptor and TGF- $\beta$ receptor are reasonable candidates and easily accessible to targeting tracer molecules because of their extracellular localization. Additionally, $\alpha_{v} \beta_{3}$ integrins are expressed in the supermature focal adhesions and might constitute yet another candidate. However, the specificity and efficacy of these targets needs to be determined because most are present on other cell types (Table 1). Abbreviations: ASMA, $\alpha$-smooth muscle actin; ATR, angiotensin II receptor; TGF- $\beta$, transforming growth factor- $\beta$.

as collagen, fibronectin and laminin, ${ }^{18}$ that replace necrotic cardiomyocytes as a scar.

\section{From fibroblast to myofibroblast}

An important stimulus for the phenotypic transition of a fibroblast to a myofibroblast is a change in the mechanical microenvironment. In intact, uninjured tissue, fibroblasts are generally protected from stress by the crosslinked ECM framework. On loss of architectural integrity as a result of injury, fibroblasts exposed to mechanical stress become proto-myofibroblasts. ${ }^{19}$ Proto-myofibroblasts are characterized by the presence of stress fibers that contain cytoplasmic $\beta$-actin and $\gamma$-actin. Subsequent exposure to TGF- $\beta 1$, mainly produced by cardiac fibroblasts, ${ }^{4}$ and the ED-A splice variant of fibronectin result in the differentiation of proto-myofibroblasts into myofibroblasts. ${ }^{20,21}$ Indeed, mice lacking the ED-A exon of the gene encoding fibronectin have been shown to display abnormal skin wound healing. ${ }^{22}$

\section{Integrin expression}

In culture, myofibroblasts develop specialized focal adhesions that are referred to as being 'supermature' to account for their markedly longer appearance compared with the classical focal adhesions of fibroblasts. In addition, supermature focal adhesions exhibit a specific molecular composition: they express high levels of vinculin, paxillin, tensin and the integrins $\alpha_{\mathrm{v}} \beta_{3}$ and $\alpha_{5} \beta_{1}{ }^{23}$ Of note, $\alpha_{\mathrm{v}} \beta_{3}$ integrin is not usually expressed in the myocardium in adults; expression is seen on endothelial cells during angiogenesis in response to angiogenic growth factors and is fundamental for endothelial cell proliferation, adhesion and survival. The integrin moieties are also expressed at high levels on myofibroblasts, and contribute to enhance the promoter activity of collagen genes and reduce the expression of genes encoding metalloproteinases. ${ }^{24}$

\section{Potential differentiation markers}

Fully differentiated myofibroblasts are characterized by the expression of $\alpha$-smooth muscle actin (ASMA) and other smooth muscle cell (SMC) differentiation markers (Figure 2, Table 1). ${ }^{25-27}$ Unlike SMCs, however, myofibroblasts express relatively low amounts of smooth muscle myosin heavy chain. ${ }^{28}$ Until approximately 5 years ago, the cytokeletal protein smoothelin was proposed as a late differentiation marker for contractile SMCs that would allow the discrimination of contractile SMCs from myofibroblasts. ${ }^{29}$ However, smoothelin and other late SMC markers have been observed in cultured lung fibroblasts treated with TGF- $\beta 1,{ }^{30}$ obscuring their discriminative value. A newly proposed differentiation marker is an isoform of the stress-fiber protein palladin that contains four immunoglobulin (4Ig) domains. The expression of 4Ig palladin in fibroblast stress fibers is strongly induced following TGF- $\beta 1$ treatment. ${ }^{31}$ However, SMCs can also express this isoform of palladin; ${ }^{32}$ therefore, palladin is also not a distinctive marker for myofibroblasts. To date, no unique markers for myofibroblasts have been identified. Hopefully, advances in proteomics might result in the identification of unique differentiation markers, provided that such markers exist.

\section{Myofibroblast migration after MI}

Leukocytes and mesenchymal cells, such as myofibroblasts, are attracted to the site of MI by various chemotactic factors, including TGF- $\beta$, which is mainly produced by cardiac fibroblasts. ${ }^{4}$ For myofibroblasts to move to the site of injury, they must continually make and break contacts with the surrounding ECM. Several studies showed that the integrin expression profile of motile myofibroblasts differs from that of resting fibroblasts. ${ }^{33}$ Activated fibroblasts have been reported to secrete stromelysin and collagenases, which help to dissolve the surrounding interstitial matrix, thereby enhancing migration. ${ }^{34}$

Migration of myofibroblasts to the damaged region is partially determined by the expression of frizzled-2 ( $f 2)$, a tissue polarity gene that encodes a seven-transmembrane protein. The expression of $f z 2$ is upregulated in myofibroblasts during their migration into the infarct area; when the cells become stationary in the newly formed scar, its expression is decreased. ${ }^{35}$

\section{Myofibroblast-mediated deposition of collagen}

After MI, new ECM proteins are deposited, first in the border zone between infarcted and noninfarcted tissue, 
and later in the central area of the infarct. Myofibroblasts produce interstitial collagens, and elevated amounts of type III collagen can already be observed 3 days after induction of MI in rats. ${ }^{36}$ The production of type I collagen occurs more slowly, and peak levels of this protein are lower than those of type III collagen. Type I collagen confers tensile strength on the infarct if multiple fibers are crosslinked," a process that is mediated by the lysyl oxidase family of enzymes. ${ }^{37}$ The expression of lysyl oxidase is upregulated during the first weeks of infarct healing and remains elevated up to 90 days after MI. ${ }^{37}$ Lysyl oxidase expression is responsive to the levels of connective tissue growth factor (CTGF) and TGF- $\beta,^{38}$ and could probably be used as a surrogate marker for the extent of myofibroblast proliferation.

\section{Contractile properties of myofibroblasts}

During wound healing in skin, myofibroblasts align perpendicular to the wound rim and their contractile properties bring wound margins closer, a phenomenon that is known as wound contraction and that minimizes the scar size. ${ }^{39}$ The reduction in size is stabilized by ECM deposition and the myofibroblasts subsequently disappear from the scar area. ${ }^{25}$ This process explains why a scar is generally considered to be an ECM-rich, acellular entity. However, unlike wound healing in the skin ${ }^{40}$ myofibroblasts can persist for up to 20 years even in healed human infarcts. ${ }^{4}$ This persistence suggests that there is a continued role for myofibroblasts in maintaining the stability of the infarct area, an area that is under repetitive stress in a beating heart. Indeed, myofibroblasts continue to produce type I and type III fibrillar collagen long after scar tissue has replaced the necrotic myocytes.

Analysis of myofibroblasts in granulation and fibrotic tissue has revealed the presence of extensive cellmatrix contacts called fibronexi; such fibronexi are not observed in fibroblasts isolated from normal connective tissue. Myofibroblast fibronexi connect intracellular microfilaments both to other myofibroblasts and to the surrounding ECM, thereby mediating contraction.

The nature of the contraction generated by the myofibroblasts is fundamentally distinct from that generated by cardiomyocytes. Myofibroblasts typically generate a sustained contraction resembling that of SMCs (such as is present in the vasculature), and this contraction can be modulated by circulating factors and neurohormones, such as angiotensin II. By contrast, cardiomyocytes contract and relax cyclically following a stimulus from the cardiac conduction system. ${ }^{17}$ Given the high electrical resistance of the connective tissue in the infarct area, ${ }^{42}$ smooth muscle-like cells, such as myofibroblasts, are better suited for tonic contraction than cardiomyocytes, because the latter cells only contract upon electrical activation whereas the former cells do not.

\section{Myofibroblast removal}

When the damaged ECM has been reconstructed, the repaired tissue may be able to partially take over the mechanical load. Although the myofibroblasts may persist for many years, ${ }^{41}$ some myofibroblasts may be removed by
Table 1 | Myofibroblast differentiation markers

\begin{tabular}{|c|c|}
\hline Marker & Cellular overlap \\
\hline \multicolumn{2}{|l|}{ Intracellular } \\
\hline Cofilin $^{71}$ & Smooth muscle cells ${ }^{72}$ \\
\hline ASMA $^{73}$ & Smooth muscle cells ${ }^{74}$ \\
\hline Palladin $4 \lg ^{73}$ & Smooth muscle cells ${ }^{32}$ \\
\hline \multicolumn{2}{|l|}{ Cell surface } \\
\hline AT1 $R^{73}$ & Cardiomyocytes/smooth muscle cells ${ }^{75}$ \\
\hline TGF- $\beta$ receptor ${ }^{73}$ & Various cells ${ }^{75}$ \\
\hline Integrins $^{69}\left(\alpha_{v} \beta_{3}, \alpha_{1} \beta_{1}, \alpha_{2} \beta_{1}, \alpha_{11} \beta_{1}\right)$ & Endothelial cells ${ }^{76}$ \\
\hline Osteoblast cadherin ${ }^{73}$ & Mesenchymal cells ${ }^{73}$ \\
\hline Frizzled-2 ${ }^{9}$ & Smooth muscle cells ${ }^{77}$ \\
\hline \multicolumn{2}{|l|}{ Extracellular matrix* } \\
\hline Collagen types I, III, IV, V, VI ${ }^{73}$ & Various cells ${ }^{73}$ \\
\hline Tenascin $\mathrm{C}^{73}$ & Smooth muscle cells ${ }^{73}$ \\
\hline Fibronectin ED-A ${ }^{73}$ & Smooth muscle cells ${ }^{78}$ \\
\hline \multicolumn{2}{|l|}{ Circulating* } \\
\hline Lysyl oxidase ${ }^{79}$ & Fibroblasts/smooth muscle cells ${ }^{79}$ \\
\hline PICP, PINP, PIIINP80 & Fibroblasts 80 \\
\hline
\end{tabular}

*Indirect markers of myofibroblast activity. Abbreviations: ASMA, $\alpha$-smooth muscle actin; AT1R, angiotensin II type 1 receptor; Palladin 4lg, palladin containing four immunoglobulin domains; PICP, C-terminal propeptide of type I procollagen; PINP, N-terminal propeptide of type I procollagen; PIIINP, $\mathrm{N}$-terminal propeptide of type III procollagen; TGF- $\beta$, transforming growth factor- $\beta$.

apoptosis, especially in poorly healed myocardial infarcts. The signals that induce apoptosis in myofibroblasts have been partially defined, with Fas, ${ }^{43,44}$ TGF- $\beta{ }^{45}$ and angiotensin II type 1 (AT1) receptor ${ }^{46}$ being implicated. The release from mechanical stress is a potent promoter of myofibroblast apoptosis in vivo. ${ }^{28}$ Adhesion-dependent survival signals are transmitted via cell-cell contacts. Studies using corneal myofibroblasts in a dense culture showed a significant decrease in the expression of ASMA, and a dedifferentiation into ASMA-negative fibroblasts was observed. ${ }^{47}$ This phenomenon has been attributed to desensitization to TGF- $\beta 1$ induced by cell-cell contact (as a result of growth at high density). ${ }^{47}$

\section{Adverse myocardial remodeling}

Well-healed infarcts contain large amounts of ECM, which can occupy up to $80 \%$ of the infarct area. ${ }^{9}$ However, collagen deposition also occurs in the uninfarcted remote myocardial region, predominantly in the interstitium, where it contributes to ventricular stiffness and dysfunction. Myocardial interstitial fibrosis directly contributes to adverse structural remodeling in various cardiovascular diseases that are associated with chronic ischemia and/ or pressure overload, as well as in some intrinsic myocardial diseases, such as hypertrophic and diabetic cardiomyopathy. In addition to interstitial alterations in the noninjured areas, replacement fibrosis, although it initially supports ventricular morphology after MI, can contribute to geometric changes and inevitable functional deterioration over time. ${ }^{48,49}$

As outlined above, phenotypically transformed myofibroblasts are central to fibrosis at sites of remodeling after MI. Various neurohumoral substances, such as 


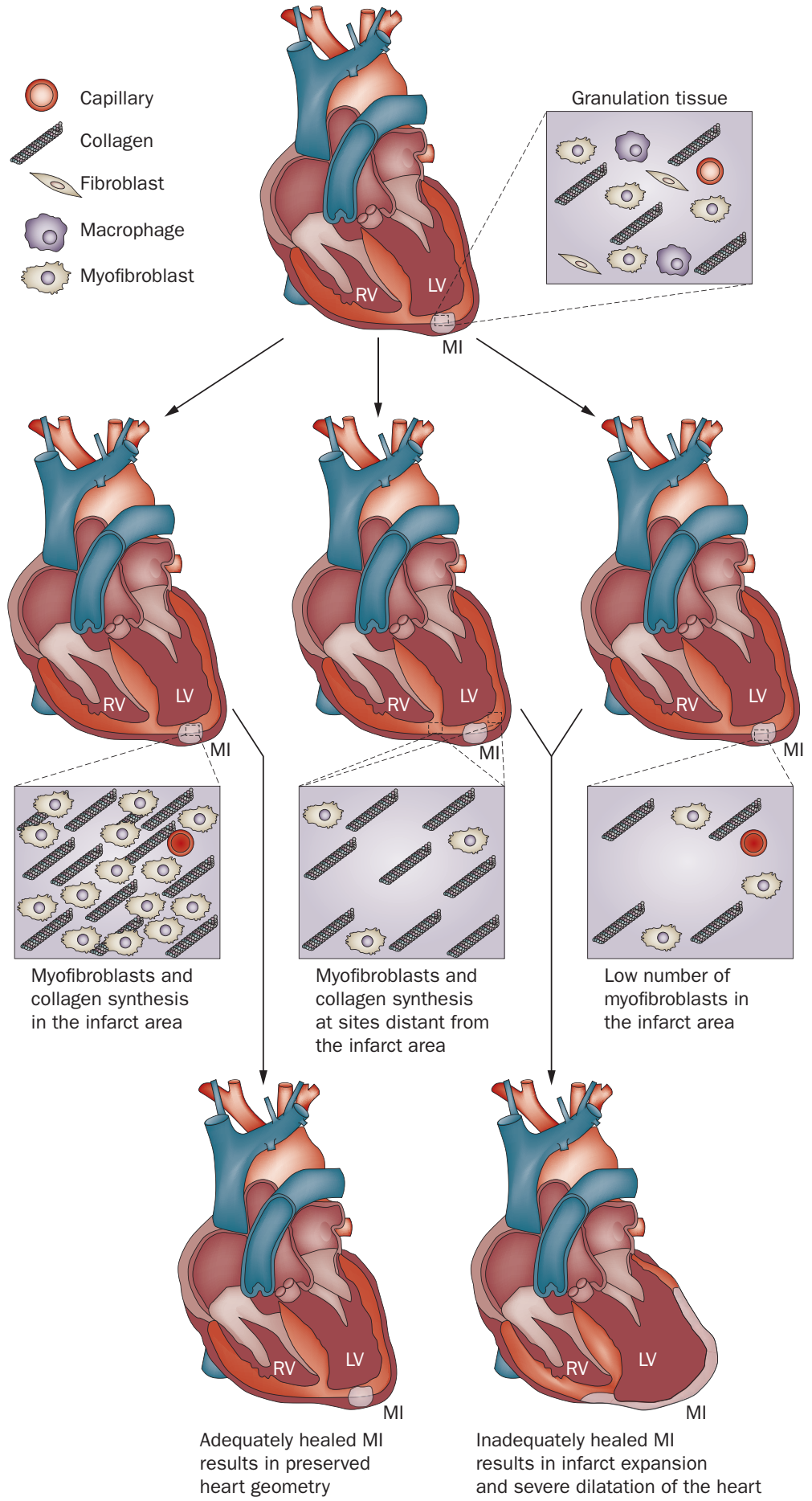

Figure 3 | The suggested role of myofibroblasts in infarct healing. Granulation tissue post-MI consists of inflammatory cells, neovascularization and fibroblastlike cells that deposit collagen. The granulation tissue matures into a scar. Adequately healed infarcts show preserved geometry, while inadequately healed infarcts (with few myofibroblasts) show severe dilatation and infarct expansion. Abbreviations: LV, left ventricle; MI, myocardial infarction; RV, right ventricle.

angiotensin II and TGF $\beta 1$, are preferentially overexpressed by cardiomyocytes at the infarct border, traverse the common interstitial space and enhance collagen synthesis at sites distant from the MI. The fibrosis that develops over time in regions remote to the infarct represents the majority of connective tissue found in ischemic cardiomyopathy, and contributes to adverse structural remodeling in the failing human heart. ${ }^{50}$ It seems reasonable to presume that an optimally healed infarcted heart should comprise a strong, ECM-rich replacement scar, but minimal remote fibrosis (Figure 3).

Myocardial upregulation of the renin-angiotensin system (RAS) contributes considerably to ventricular remodeling. Overexpression of the AT1 receptor in the myocardium is associated with interstitial fibrosis, ${ }^{51}$ and AT1-receptor-deficient transgenic mice exhibit minimal structural remodeling after MI. ${ }^{52}$ The administration of angiotensin receptor blockers during MI prevents and/ or restricts ventricular remodeling, and thereby reduces morbidity and mortality after MI, regardless of left ventricular functional deterioration. ${ }^{53-57}$ Angiotensin II, which is produced locally by activated macrophages, cardiomyocytes and myofibroblasts, exerts its effect by directly stimulating TGF- $\beta 1$ production. ${ }^{42}$ Ongoing expression of angiotensin II and AT1 receptors, and active TGF- $\beta 1$ and TGF- $\beta 1$ receptors, is observed in infarcted rodent hearts months after MI, and underscores the persistent metabolic activity of activated myofibroblasts. ${ }^{42}$ TGF- $\beta 1$ signaling results in the production by cardiac myofibroblasts of interstitial collagens, fibronectin and proteoglycans. It also stimulates its own production in myofibroblasts, thereby establishing an autocrine cycle of myofibroblastic differentiation and activation. ${ }^{11}$ Studies have shown that overexpression of TGF- $\beta 1$ in transgenic mice can lead to cardiac hypertrophy, which is characterized by both interstitial fibrosis and hypertrophic growth of cardiac myocytes. ${ }^{58}$ Although expressed at high levels on myofibroblasts, the components of RAS and TGF- $\beta 1$ signaling can, of course, also be found on other cells.

Therapy using an angiotensin-converting enzyme (ACE) inhibitor, an angiotensin receptor blocker, or both has been shown to have a beneficial effect on infarct healing: the treatment contributes to maturation of collagen tissue in the infarct zone but preferentially reduces the extent of collagen deposition in the remote myocardium. ${ }^{59}$ This approach allows for a balanced influence on ventricular mechanics, and is consistent with the clinical outcomes achieved in patients appropriately treated using antagonists of the RAS. ${ }^{60}$

\section{Development of heart failure}

Heart failure is a frequent complication of MI that is associated with adverse remodeling. ${ }^{61}$ Owing to improved survival post-MI, more and more people are at risk of developing heart failure. Within 6 years of the clinical event of acute MI, $22 \%$ of male and $46 \%$ of female patients develop heart failure. ${ }^{62}$ The loss of ventricular muscle during MI and the subsequent complex architectural alterations involving both the infarcted and noninfarcted myocardium contribute to the evolution of heart failure. Wall thinning and infarct expansion are the most prominent changes in the infarct region, ${ }^{63}$ and can lead to both systolic (decreased contraction) and diastolic (decreased relaxation) dysfunction. ${ }^{64}$ Ventricular dilatation might initially function as a compensatory mechanism to maintain stroke volume after the loss of contractile tissue. However, 
this precarious balance can be exceeded: increased cavity volume with insufficient compensatory hypertrophy results in increased loading conditions, promoting further enlargement and dysfunction. Patients showing extensive infarct expansion after MI are more likely to develop heart failure. ${ }^{65}$ In those who are likely to develop heart failure after MI, a low numbers of myofibroblasts in the infarct area-predicting poor ECM maintenance and excessive scar dilatation-or excessive amounts of fibroblasts in the uninjured parts of the heart, indicative of fibrosis of the noninfarcted myocardium, are expected (Figure 3 ). A role for myofibroblasts in the prevention of dilatation post-MI has been proposed. ${ }^{66}$ Myofibroblasts have contractile properties and might prevent infarct expansion; as mentioned above, they can persist in human infarcts for decades post-MI. ${ }^{41}$

\section{Imaging of myofibroblasts}

As myofibroblasts are recruited to accomplish myocardial fibrosis, it is logical to propose that identification of unique markers expressed by these cells might provide an opportunity to design imaging strategies to enable the early detection of adverse remodeling and to predict the likelihood of developing heart failure. Myofibroblasts express several markers, but none of these are, unfortunately, sufficiently specific to myofibroblasts (Table 1). ${ }^{67}$

Only a few membrane or transmembrane moieties expressed on myofibroblasts are potential targets for molecular imaging but should, nevertheless, be easily accessible to appropriately-labeled specific ligands. Fz2 is located on the plasma membrane and, as discussed, is upregulated in myofibroblasts as they migrate into the infarct area. AT1 receptors are expressed two-to-threefold higher in myofibroblasts, compared with background. ${ }^{68}$ Because of the persistent expression of AT1 receptors on myofibroblasts, these molecules might be suitable targets for molecular imaging. Indeed, a peptide analog of angiotensin labeled with a fluorescent tracer has been used to follow the myocardial upregulation of AT receptors in a murine MI model (Figure 4$).{ }^{68}$ Other RAS proteins, such as renin and ACE, are excreted and so are not very suitable as targets for molecular imaging. TGF- $\beta 1$ receptors could, however, also be potential targets for molecular imaging. Furthermore, integrin targeting-for example, targeting of $\alpha_{1} \beta_{1}, \alpha_{2} \beta_{1}, \alpha_{11} \beta_{1}$ and $\alpha_{\mathrm{v}} \beta_{3}$-might be another reasonable approach for molecular imaging, ${ }^{69}$ RGD probes, which bind to integrins such as $\alpha_{v} \beta_{3}$, have been used to identify myofibroblastic proliferation in post-infarct animal model ${ }^{59}$ as well as in clinical studies. ${ }^{70}$

In addition to identifying relatively exclusive membrane markers of myofibroblasts, targeting molecules that are expressed at certain stages of healing might also prove worthwhile. For example, lysyl oxidase, which mediates collagen crosslinking, could potentially be used as a surrogate marker for the extent of myofibroblast activity. Furthermore, cofilin is proposed as a marker for myofibroblasts. Cofilin has been demonstrated in valve myofibroblasts but is also present in SMCs and, therefore, is not a specific myofibroblasts marker. ${ }^{71,72}$
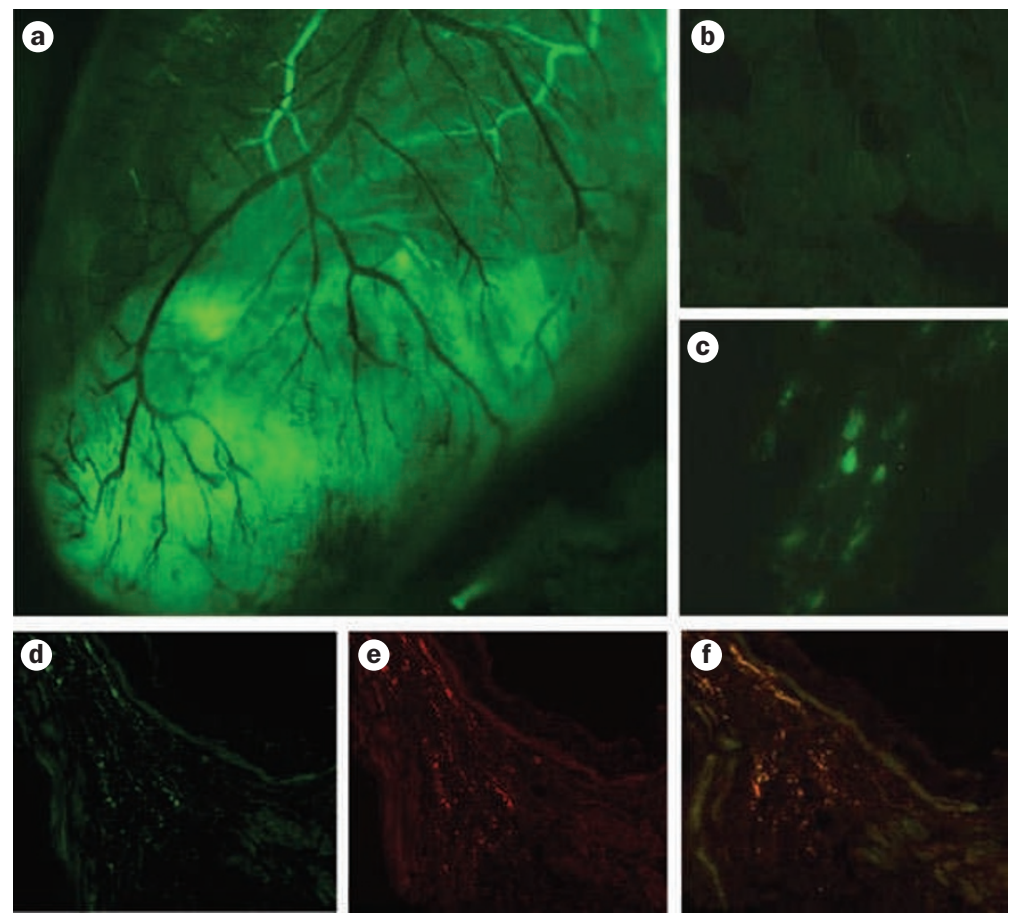

Figure 4 | Optical imaging of ATRs in a mouse model of MI 3 weeks post-infarction. a | Uptake of a fluorescently labeled peptide analog of angiotensin was observed in the infarct area. Sections through the affected heart show $\mathbf{b} \mid$ no uptake of the analog in the remote zone and c | clear uptake of the analog in nonmyocytic cells in the infarct region. $\mathbf{d}-\mathbf{f} \mid$ ATR-positive cells (panel $d$, green), also stained positive for ASMA (panel e, red), indicating that ATRs are present on myofibroblasts (panel f, yellow). Abbreviations: ASMA, a-smooth muscle actin, ATR, angiotensin II receptor; MI, myocardial infarction.

\section{Conclusions}

Myofibroblasts are integrally involved in myocardial healing after MI. These cells produce collagen, which is expected to stabilize the damaged and lost tissue, and prevent infarct expansion and ventricular dysfunction after its deposition in the myocardial void. However, concurrent proliferation of fibroblasts in noninjured myocardial regions results in adverse ventricular remodeling and development of heart failure over time. The optimal pharmacologic manipulation is expected to increase myofibroblast integrity and function in the infarct area and simultaneously preventing myofibroblast differentiation in the remote areas. Molecular imaging may help clarify such pathogenetic mechanisms of infarct healing and heart failure volution. It may also allow prognostication after MI as well as monitoring of the efficacy of pharmacological interventions aimed at the primary prevention of heart failure.

\section{Review criteria}

We searched for original articles and review papers focusing on myofibroblasts in MEDLINE and PubMed published between 1970 and 2009. The search terms we used were "myofibroblasts", "myocardial infarction", "differentiation markers" and "fibroblasts". All papers identified were English-language full-text papers. We also searched the reference lists of identified articles for further papers. 
1. Hein, S. \& Schaper, J. The extracellular matrix in normal and diseased myocardium. J. Nucl. Cardiol. 8, 188-196 (2001).

2. Medugorac, I. Characterization of intramuscular collagen in mammalian left ventricle. Basic Res. Cardiol. 77, 589-598 (1982).

3. Camelliti, P., Borg, T. K. \& Kohl, P. Structural and functional characterisation of cardiac fibroblasts. Cardiovasc. Res. 65, 40-51 (2005).

4. Porter, K. E. \& Turner, N. A. Cardiac fibroblasts: at the heart of myocardial remodeling. Pharmacol. Ther. 123, 255-278 (2009).

5. Leask, A. \& Abraham, D. J. TGF-beta signaling and the fibrotic response. FASEB J. 18, 816-827 (2004).

6. Prockop, D. J. \& Kivirikko, K. I. Collagens: molecular biology, diseases, and potentials for therapy. Annu. Rev. Biochem. 64, 403-434 (1995).

7. Kagan, H. M. \& Trackman, P. C. Properties and function of lysyl oxidase. Am. J. Respir. Cell. Mol. Biol. 5, 206-210 (1991).

8. Shapiro, S. D. Matrix metalloproteinase degradation of extracellular matrix: biological consequences. Curr. Opin. Cell Biol. 10, 602-608 (1998).

9. Cleutjens, J. P., Blankesteijn, W. M., Daemen, M. J. \& Smits, J. F. The infarcted myocardium: simply dead tissue, or a lively target for therapeutic interventions. Cardiovasc. Res. 44, 232-241 (1999).

10. Brown, R. D., Ambler, S. K., Mitchell, M. D. \& Long, C. S. The cardiac fibroblast: therapeutic target in myocardial remodeling and failure. Annu. Rev. Pharmacol. Toxicol. 45, 657-687 (2005).

11. Wynn, T. A. Cellular and molecular mechanisms of fibrosis. J. Pathol. 214, 199-210 (2008).

12. Kalluri, R. \& Neilson, E. G., Epithelialmesenchymal transition and its implications for fibrosis. J. Clin. Invest. 112, 1776-1784 (2003).

13. Zeisberg, E. M. et al.

Endothelial-to-mesenchymal transition contributes to cardiac fibrosis. Nat. Med. 13, 952-961 (2007).

14. Bucala, R., Spiegel, L. A., Chesney, J., Hogan, M. \& Cerami, A. Circulating fibrocytes define a new leukocyte subpopulation that mediates tissue repair. Mol. Med. 1, 71-81 (1994).

15. Iwano, M. et al. Evidence that fibroblasts derive from epithelium during tissue fibrosis. J. Clin. Invest. 110, 341-350 (2002).

16. Chang, H. Y. et al. Diversity, topographic differentiation, and positional memory in human fibroblasts. Proc. Natl Acad. Sci. USA 99, 12877-12882 (2002).

17. Tomasek, J. J., Gabbiani, G., Hinz, B., Chaponnier, C. \& Brown, R. A. Myofibroblasts and mechano-regulation of connective tissue remodelling. Nat. Rev. Mol. Cell Biol. 3, 349-363 (2002).

18. Squires, C. E. et al. Altered fibroblast function following myocardial infarction. J. Mol. Cell Cardiol. 39, 699-707 (2005).

19. Hinz, B. \& Gabbiani, G. Mechanisms of force generation and transmission by myofibroblasts. Curr. Opin. Biotechnol. 14, 538-546 (2003).

20. Serini, G. et al. The fibronectin domain ED-A is crucial for myofibroblastic phenotype induction by transforming growth factor-beta1. J. Cell Biol. 142, 873-881 (1998).

21. Wang, J., Chen, H., Seth, A. \& McCulloch, C. A. Mechanical force regulation of myofibroblast differentiation in cardiac fibroblasts. Am. J. Physiol. Heart Circ. Physiol. 285, H1871-H1881 (2003).

22. Muro, A. F. et al. Regulated splicing of the fibronectin EDA exon is essential for proper skin wound healing and normal lifespan. J. Cell Biol. 162, 149-160 (2003).

23. Hinz, B. Masters and servants of the force: the role of matrix adhesions in myofibroblast force perception and transmission. Eur. J. Cell Biol. 85, 175-181 (2006).

24. Asano, Y. et al. Increased expression of integrin alpha(v)beta3 contributes to the establishment of autocrine TGF-beta signaling in scleroderma fibroblasts. J. Immunol. 175, 7708-7718 (2005).

25. Gabbiani, G. The myofibroblast in wound healing and fibrocontractive diseases. J. Pathol. 200, 500-503 (2003).

26. Virag, J. I. \& Murry, C. E. Myofibroblast and endothelial cell proliferation during murine myocardial infarct repair. Am. J. Pathol. 163, 2433-2440 (2003).

27. Foo, I. T., Naylor, I. L., Timmons, M. J. \& Trejdosiewicz, L. K. Intracellular actin as a marker for myofibroblasts in vitro. Lab. Invest. 67, 727-733 (1992).

28. Hinz, B. et al. The myofibroblast: one function, multiple origins. Am. J. Pathol. 170, 1807-1816 (2007).

29. van Eys, G. J., Niessen, P. M. \& Rensen, S. S. Smoothelin in vascular smooth muscle cells. Trends Cardiovasc. Med. 17, 26-30 (2007).

30. Chambers, R. C., Leoni, P., Kaminski, N., Laurent, G. J. \& Heller, R. A. Global expression profiling of fibroblast responses to transforming growth factor-beta1 reveals the induction of inhibitor of differentiation-1 and provides evidence of smooth muscle cell phenotypic switching. Am. J. Pathol. 162, 533-546 (2003).

31. Ronty, M. J. et al. Isoform-specific regulation of the actin-organizing protein palladin during TGF-beta1-induced myofibroblast differentiation. J. Invest. Dermatol. 126, 2387-2396 (2006).

32. Mykkanen, O. M. et al. Characterization of human palladin, a microfilament-associated protein. Mol. Biol. Cell 12, 3060-3073 (2001).

33. Paine, R., 3rd \& Ward, P. A. Cell adhesion molecules and pulmonary fibrosis. Am. J. Med. 107, 268-279 (1999).

34. Kuncio, G. S., Neilson, E. G. \& Haverty, T. Mechanisms of tubulointerstitial fibrosis. Kidney Int. 39, 550-556 (1991).

35. Blankesteijn, W. M., Essers-Janssen, Y. P., Verluyten, M. J., Daemen, M. J. \& Smits, J. F. A homologue of Drosophila tissue polarity gene frizzled is expressed in migrating myofibroblasts in the infarcted rat heart. Nat. Med. 3 , 541-544 (1997).

36. Cleutjens, J. P., Verluyten, M. J., Smiths, J. F. \& Daemen, M. J. Collagen remodeling after myocardial infarction in the rat heart. Am. J. Pathol. 147, 325-338 (1995).

37. Smith-Mungo, L. I. \& Kagan, H. M. Lysyl oxidase: properties, regulation and multiple functions in biology. Matrix Biol. 16, 387-398 (1998).

38. Hong, H. H., Uzel, M. I., Duan, C., Sheff, M. C. \& Trackman, P. C. Regulation of lysyl oxidase, collagen, and connective tissue growth factor by TGF-beta1 and detection in human gingiva. Lab. Invest. 79, 1655-1667 (1999).

39. Gabbiani, G., Hirschel, B. J., Ryan, G. B., Statkov, P. R. \& Majno, G. Granulation tissue as a contractile organ. A study of structure and function. J. Exp. Med. 135, 719-734 (1972).

40. Desmouliere, A., Redard, M., Darby, I. \& Gabbiani, G. Apoptosis mediates the decrease in cellularity during the transition between granulation tissue and scar. Am. J. Pathol. 146, 56-66 (1995).

41. Willems, I. E., Havenith, M. G., De Mey, J. G. \& Daemen, M. J. The alpha-smooth muscle actinpositive cells in healing human myocardial scars. Am. J. Pathol. 145, 868-875 (1994).
42. Sun, Y., Kiani, M. F., Postlethwaite, A. E. \& Weber, K. T. Infarct scar as living tissue. Basic Res. Cardiol. 97, 343-347 (2002).

43. Li, Y. et al. Critical roles for the Fas/Fas ligand system in postinfarction ventricular remodeling and heart failure. Circ. Res. 95, 627-636 (2004).

44. von Harsdorf, R. "Fas-ten" your seat belt: antiapoptotic treatment in heart failure takes off. Circ. Res. 95, 554-556 (2004).

45. Okada, H. et al. Postinfarction gene therapy against transforming growth factor-beta signal modulates infarct tissue dynamics and attenuates left ventricular remodeling and heart failure. Circulation 111, 2430-2437 (2005).

46. Kanamori, H. et al. Inhibition of Fas-associated apoptosis in granulation tissue cells accompanies attenuation of postinfarction left ventricular remodeling by olmesartan. Am. J. Physiol. Heart Circ. Physiol. 292, H2184-2194 (2007).

47. Petridou, S., Maltseva, O., Spanakis, S. \& Masur, S. K. TGF-beta receptor expression and smad2 localization are cell density dependent in fibroblasts. Invest. Ophthalmol. Vis. Sci. 41, 89-95 (2000).

48. Opie, L. H., Commerford, P. J., Gersh, B. J. \& Pfeffer, M. A. Controversies in ventricular remodelling. Lancet 367, 356-367 (2006).

49. Schocken, D. D. et al. Prevention of heart failure: a scientific statement from the American Heart Association Councils on Epidemiology and Prevention, Clinical Cardiology, Cardiovascular Nursing, and High Blood Pressure Research; Quality of Care and Outcomes Research Interdisciplinary Working Group; and Functional Genomics and Translational Biology Interdisciplinary Working Group. Circulation 117, 2544-2565 (2008).

50. Beltrami, C. A. et al. Structural basis of endstage failure in ischemic cardiomyopathy in humans. Circulation 89, 151-163 (1994).

51. Weber, K. T., Sun, Y. \& Katwa, L. C. Myofibroblasts and local angiotensin II in rat cardiac tissue repair. Int. J. Biochem. Cell Biol. 29, 31-42 (1997).

52. Harada, K., Sugaya, T., Murakami, K., Yazaki, Y. $\&$ Komuro, I. Angiotensin II type 1 A receptor knockout mice display less left ventricular remodeling and improved survival after myocardial infarction. Circulation 100, 2093-2099 (1999).

53. Pfeffer, M. A. et al. Effects of candesartan on mortality and morbidity in patients with chronic heart failure: the CHARM-Overall programme. Lancet 362, 759-766 (2003).

54. Pitt, B. et al. Effect of losartan compared with captopril on mortality in patients with symptomatic heart failure: randomised trial-the Losartan Heart Failure Survival Study ELITE II. Lancet 355, 1582-1587 (2000).

55. Cohn, J. N. \& Tognoni, G. A randomized trial of the angiotensin-receptor blocker valsartan in chronic heart failure. N. Engl. J. Med. 345, 1667-1675 (2001).

56. Effects of enalapril on mortality in severe congestive heart failure. Results of the Cooperative North Scandinavian Enalapril Survival Study (CONSENSUS). The CONSENSUS Trial Study Group. N. Engl. J. Med. 316 , 1429-1435 (1987).

57. Effect of enalapril on survival in patients with reduced left ventricular ejection fractions and congestive heart failure. The SOLVD Investigators. N. Engl. J. Med. 325, 293-302 (1991).

58. Rosenkranz, S. et al. Alterations of betaadrenergic signaling and cardiac hypertrophy in transgenic mice overexpressing TGF-beta(1) Am. J. Physiol. Heart Circ. Physiol. 283, H1253-H1262 (2002). 
59. van den Borne, S. W. et al. Molecular imaging of interstitial alterations in remodeling myocardium after myocardial infarction. J. Am. Coll. Cardiol. 52, 2017-2028 (2008).

60. Landmesser, U., Wollert, K. C. \& Drexler, H. Potential novel pharmacological therapies for myocardial remodelling. Cardiovasc. Res. 81, 519-527 (2009).

61. Katz, A. M. The cardiomyopathy of overload: an unnatural growth response. Eur. Heart J. 16 (Suppl. 0), 110-114 (1995).

62. Rosamond, W. et al. Heart disease and stroke statistics-2008 update: a report from the American Heart Association Statistics Committee and Stroke Statistics Subcommittee. Circulation 117, e25-146 (2008).

63. Weisman, H. F., Bush, D. E., Mannisi, J. A. Weisfeldt, M. L. \& Healy, B. Cellular mechanisms of myocardial infarct expansion. Circulation 78 , 186-201 (1988).

64. Gaasch, W. H. Diagnosis and treatment of heart failure based on left ventricular systolic or diastolic dysfunction. JAMA 271, 1276-1280 (1994).

65. Pfeffer, M. A. \& Braunwald, E. Ventricular remodeling after myocardial infarction. Experimental observations and clinical implications. Circulation 81, 1161-1172 (1990).

66. van den Borne, S. W. et al. Mouse strain determines the outcome of wound healing after myocardial infarction. Cardiovasc. Res. 84, 273-282 (2009).
67. Eyden, B. The myofibroblast: a study of normal, reactive and neoplastic tissues, with an emphasis on ultrastructure. J. Submicrosc. Cytol. Pathol. 7-166 (2007).

68. Verjans, J. W. H. et al. Noninvasive imaging of angiotensin receptores after myocardial infarction. J. Am. Coll. Cardiol. Cardiovasc. Imaging 1, 354-362 (2008).

69. Ng, C. P., Hinz, B. \& Swartz, M. A. Interstitial fluid flow induces myofibroblast differentiation and collagen alignment in vitro. J. Cell Sci. 118, 4731-4739 (2005).

70. Verjans, J. W. et al. Imaging avb3/b5 integrin upregulation in patients after myocardial infarction [abstract 3288]. Circulation 116, II_740 (2007).

71. Pho, M. et al. Cofilin is a marker of myofibroblast differentiation in cells from porcine aortic cardiac valves. Am. J. Physiol. Heart Circ. Physiol. 294, H1767-H1778 (2008).

72. Gerthoffer, W. T. Mechanisms of vascular smooth muscle cell migration. Circ. Res. 100, 607-621 (2007).

73. Hinz, B. Formation and function of the myofibroblast during tissue repair. J. Invest. Dermatol. 127, 526-537 (2007).

74. Yamamoto, Y., Kubota, T., Atoji, Y. \& Suzuki, Y. Distribution of alpha-vascular smooth muscle actin in the smooth muscle cells of the gastrointestinal tract of the chicken. J. Anat. 189 (Pt 3), 623-630 (1996).

75. Rosenkranz, S. TGF-beta1 and angiotensin networking in cardiac remodeling. Cardiovasc. Res. 63, 423-432 (2004).
76. Urbich, C. \& Dimmeler, S. Endothelial progenitor cells: characterization and role in vascular biology. Circ. Res. 95, 343-353 (2004).

77. Castoldi, G. et al. Angiotensin II modulates frizzled-2 receptor expression in rat vascular smooth muscle cells. Clin. Sci. (Lond.) 108, 523-530 (2005).

78. Glukhova, M. A. et al. Expression of extra domain A fibronectin sequence in vascular smooth muscle cells is phenotype dependent. J. Cell Biol. 109, 357-366 (1989).

79. Reynaud, C., Gleyzal, C., Jourdan-Le Saux, C. \& Sommer, P. Comparative functional study of the lysyl oxidase promoter in fibroblasts, Rastransformed fibroblasts, myofibroblasts and smooth muscle cells. Cell. Mol. Biol. (Noisy-le-grand) 45, 1237-1247 (1999)

80. Zannad, F., Alla, F., Dousset, B., Perez, A. \& Pitt, B. Limitation of excessive extracellular matrix turnover may contribute to survival benefit of spironolactone therapy in patients with congestive heart failure: insights from the randomized aldactone evaluation study (RALES). Rales Investigators. Circulation 102, 2700-2706 (2000).

\section{Acknowledgments}

This article is dedicated to the memory of the late Lovhaug Dagfinn, PhD, who helped to develop the RGD imaging agents described herein for myofibroblast imaging. The authors also gratefully acknowledge all their colleagues for their contributions in this research area. 